\title{
Nonspecificity of chronic soft tissue pain syndromes
}

\author{
Eldon Tunks MD FRCPC
}

\section{E Tunks. \\ Nonspecificity of chronic soft tissue pain syndromes. Pain Res Manage 1997;2(3):176-180.}

Persistent (or chronic) pain occurs with a prevalence of about $10 \%$ in the adult population, and chronic soft tissue pain is especially problematic. Criteria for diagnosis of these soft tissue pain disorders appear to suffer from specificity problems, even though they appear to be sensitive in distinguishing normal from soft tissue pain sufferers. A few decades ago the term 'neuraesthenia' was used as a diagnosis in individuals who now would probably be diagnosed as suffering from fibromyalgia, chronic fatigue and anxiety disorders with fatigue. Soft tissue pain provokes skepticism, especially among third-party payers, and controversy among clinicians. Recent epidemiological studies have demonstrated sex differences in the prevalence of widespread pain and multiple tender points, which are distributed variably throughout the adult population and tend to be correlated with subjective symptoms. Although there is a tendency for these syndromes to persist, follow-up studies show that they tend to vary in extent and sometimes show remissions over longer follow-up, casting doubt about the distinctions between chronic diffuse pains and localized chronic soft tissue pains. Because both accidents and soft tissue pains are relatively prevalent problems, the possibility of chance coincidence of accident and chronic soft tissue pain in an individual creates the need to be cautious in attributing these syndromes to specific accidents in medicolegal situations. At the same time, the available evidence does not support a generally dismissive attitude towards these patients.

Key Words: Diagnostic criteria, Epidemiological evidence, Soft tissue pain

\section{Non spécificité des syndromes douloureux chroniques des tissus mous}

RÉSUMÉ : On estime que la douleur persistante (ou chronique) a une prévalence d'environ $10 \%$ dans la population adulte, et dans cette dernière, la douleur chronique des tissus mous pose particulièrement problème. Les critères de diagnostic de ces troubles douloureux chroniques des tissus mous semblent manquer de spécificité, même si ces critères établissent une distinction entre les individus souffrant de douleurs des tissus mous et les sujets ne manifestant pas de douleur. Il y a quelques dizaines d'années, on utilisait le terme « neurasthénie » comme diagnostic chez des individus qui, de nos jours, seraient probablement diagnostiqués comme souffrant de fibromyalgie, de fatigue chronique et de troubles anxieux accompagnés de fatigue. Ceci provoque un certain scepticisme, surtout parmi les organismes de tiers payant, et fait l'objet d'une controverse parmi les cliniciens. De récentes études épidémiologiques ont démontré des différences liées au sexe dans la prévalence de la douleur généralisée et des points douloureux multiples, qui sont distribuées de façon variable à travers la population adulte et qui semble corréler avec des symptômes subjectifs. Bien que ces syndromes aient tendance à persister, des études de suivi démontrent que leur durée a tendance à varier et qu'on observe parfois des rémissions au cours d'un suivi plus long, ce qui jette un doute sur les distinctions entre les douleurs chroniques diffuses et les douleurs chroniques localisées aux tissus mous. Parce que les accidents et les douleurs des tissus mous sont des problèmes relativement courants, la possibilité d'une coïncidence fortuite d'un accident et d'une douleur chronique des tissus mous chez un même individu nécessite une certaine prudence pour attribuer ces syndromes à des accidents spécifiques dans les situations médico-légales. En même temps, les preuves disponibles ne sont pas en faveur d'une attitude généralement dédaigneuse envers ces patients.
$\mathrm{P}$ ersistent (or chronic) pain occurs with a prevalence of about $10 \%$ in the adult population, and chronic soft tissue pain is especially problematic. Criteria for diagnosis of soft tissue pain disorders suffer from specificity problems, even though they appear to be sensitive in distinguishing between normal and soft tissue pain sufferers.

\section{THE PROBLEM OF DIAGNOSIS IN CHRONIC SOFT TISSUE PAIN}

We are contending with an increasing number of terms or labels for poorly understood chronic conditions such as chronic fibromyalgia, fibrositis, myofascial pain, chronic pain syndrome, chronic fatigue syndrome, myalgic encephalomyelitis, nonarticular rheuma-

This paper is based on a presentation at a workshop on consciousness, pain and behaviour at the annual meeting of the Canadian Pain Society,

May 22, 1997, at Niagara-on-the-Lake, Ontario

McMaster University, Hamilton, Ontario

Correspondence: Dr Eldon Tunks, Room 165, Chedoke Rehabilitation Center, Sanatorium Road, Box 2000, Hamilton, Ontario L8N 375. Telephone 905-521-2100 ext 7038, fax 905-521-7927,e-mail etunks@tor.hookup.net

Recieved for publication July 27, 1997. Accepted August 4, 1997 
tism, psychogenic rheumatism, post-traumatic stress disorder, repetitive strain injury (RSI) and sympathetic-mediated pain. The following are common to all of these conditions: persistent soft tissue pain, an obscure relationship to a specific injury, an obscure mechanism of pain and illness, and problems in correlating organic disturbance with the apparent functional impairment or subjective distress.

\section{Economic considerations}

In a review of long term disability (LTD) files at London Life, Cameron (1) found that fibromyalgia was found in $11.2 \%$ of the musculoskeletal claims, representing $2.8 \%$ of all group LTD claims. RSI was found in $7.6 \%$ of all musculoskeletal claims, representing $1.9 \%$ of all group LTD claims. Chronic fatigue syndrome was found in $1 \%$ of all group LTD claims. Extrapolating from London Life's market share, it was estimated that, in Canada, group LTD carriers paid out $\$ 46$ million for fibromyalgia claims, \$30 million for repetitive strain injury claims and $\$ 27$ million for chronic fatigue claims in 1994. Facts such as these influence the attitude of the public, and the health care and legal professions towards these chronic pain diagnoses.

In Australia, economic factors apparently influenced the prevalence and choice of the diagnosis of RSI - a condition attributed vaguely to repetitive motion and uncomfortable working positions during employment. It was often diagnosed without specifying the actual injury event or the disturbed physiology, and was often diagnosed presumptively, without confirmatory medical tests, on the basis of symptoms. When RSI was deemed a compensible problem, the prevalence of this diagnosis rose precipitously. When the validity of RSI as a compensable problem was challenged, the prevalence of the diagnosis fell significantly because it was no longer politically or economically correct (2).

\section{Acute versus chronic pain}

Part of the problem in the diagnosis of chronic painful conditions has to do with the distinction between 'acute' and 'chronic' pain. When tissue is newly injured, pain arises from a variety of local and physiological mechanisms. Healing of the tissues runs a specific time-course, during which the disrupted anatomy is repaired and the altered basic physiology is restored to normal. Depending on which tissues were injured, this usually takes from five days to five weeks and very rarely might continue for as long as three months, but certainly by eight weeks the majority of injuries and wounds heal almost completely. Hence, 'acute' pain is not expected to persist beyond a few days to a few weeks.

Beyond three months, if pain persists it is probably not due to the healing and inflammation process. Many other mechanisms might be responsible for persistent ('chronic') pain that outlasts the healing process, including physiological changes in pain threshold, central nervous system plasticity changes, sensitive nerve endings in scars, mechanical factors, changes in injured musculoskeletal tissues, altered patterns of movement or conditioning, iatrogenic complications or psychological factors. Often, the persistent pain problem has several contributing causes. The longer the pain persists, the less the pain tends to correlate with the original injury and the greater the number of contributing causes; for example, the probability of serious depressive or anxiety disorders approximately doubles over several years after the onset of persistent pain $(3,4)$. This psychological comorbidity aggravates the distress and often confuses the clinical picture, with some patients being markedly affected despite apparently minor 'objective' findings and some showing little correlation between disability and pain, and little correlation between types of 'injury' and original sites of pain.

\section{Chronic pain disorder}

\section{DIAGNOSTIC CRITERIA} OF SPECIFIC DISORDERS

Since the publication of the Diagnostic and Statistical Manual of Mental Disorders (DSM) IV (5), chronic pain disorder has become an accepted Axis I (psychiatric) diagnosis and has the following characteristics.

Pain in one or more anatomical sites is the predominant focus of clinical presentation and is of sufficient severity to warrant clinical attention.

Pain causes clinically significant distress or impairment in social, occupational or other important areas of functioning.

Psychological factors are judged to have an important role in the onset, severity, exacerbation or maintenance of the pain.

The symptoms or deficit are not apparently intentionally produced or feigned.

Pain is not better accounted for by another psychiatric condition.

Pain is of six months or longer duration.

Probable causes are also considered in the diagnosis.

Pain may be associated with psychological factors that are judged to have a major role in the onset, severity, exacerbation or maintenance of the pain.

Pain may be associated with a general medical condition that has a major role in the onset, severity, exacerbation or maintenance of the pain.

Both psychological and general medical conditions may be judged to have a major role in the onset, severity, exacerbation or maintenance of the pain.

\section{Chronic fibromyalgia or fibrositis}

Chronic fibromyalgia is not a term classified by the DSM, but it has currency in the rheumatology literature. The term is used almost interchangeably with 'fibrositis' or 'nonarticular rheumatism'. Various diagnostic criteria have been proposed; some have been validated empirically. The most generally used criteria were developed as the result of a multicentre study (6).

There is persistent widespread (diffuse) pain of at least three months' duration.

This widespread pain includes the areas of the neck, thorax and/or lower back, the right and left side, and upper and lower body. (This implies that at least three of the four main body quadrants are painful.) 
Pain is evoked by palpation with $4 \mathrm{~kg}$ pressure in at least 11 of 18 prescribed tender points. (Some experts have suggested that during the examination 'control points' should be less tender than prescribed 'tender points', but this is not warranted because 'control points' are often also tender in chronic fibromyalgia.)

Other alternative diagnostic criteria identify alternative lists of diagnostic 'tender points' and give greater emphasis to subjective symptoms including nonrestorative sleep, fatigue, and depression or psychological distress, and associated conditions such as irritable bowel syndrome and chronic headache (7-9). Although the American College of Rheumatology (ACR) criteria (6) focus exclusively on tender point count and existence of persistent widespread pain for diagnosis of chronic fibromyalgia, there is some evidence that subjective factors such as nonrestorative sleep, fatigue and depression are of prognostic significance in chronic fibromyalgia (10). This association of subjective factors with prognosis is consistent with epidemiological data concerning the outcome of chronic pain in general (11). Hence, it may be prudent to rethink the choice of criteria when dealing with 'chronic fibromyalgia'.

When the ACR criteria for fibromyalgia (6) are used to compare chronic fibromyalgia patients with nonpainful controls, the criteria perform well, showing acceptable specificity and sensitivity. However, when these criteria are used in a design comparing chronic fibromyalgia with other chronic pain categories, sensitivity and specificity remain good with respect to distinguishing patients from normals, but specificity in distinguishing between pain categories is very poor (12).

\section{Myofascial pain}

Myofascial pain as a concept has been evolving for about 60 years, arising especially from early studies of referred pain and paresthesiae (altered sensation) from local noxious stimulation of deep tissue (13-15). The concept was developed into a theory of pain and pain treatment by the work of Travell and Rinzler (16) and Travell and Simons (17).

According to Simons (18), to diagnose myofascial pain there should be a 'trigger point', defined by all five of the following major criteria:

regional pain complaint;

pain or paraesthesiae in the typical distribution of that trigger point;

taut band if the muscle is accessible to palpation;

exquisite tenderness found in the taut band; and

restricted range of motion in the affected muscle.

There should also be at least one of the following three minor criteria:

reproduction of patient's clinical pain complaint by pressure on the trigger point;

local twitch response in the taut band; or

'stretch and spray' or injection alleviates the trigger point.
Travell and Simons (17) state that myofascial pain arises from injury or repetitive strains and, hence, is often a more acute condition than chronic fibromyalgia. Although the concept of myofascial pain has wide currency, these criteria have never been tested for test-retest and inter-rater reliability, or sensitivity and specificity in a properly controlled trial. Where the criteria on which chronic fibromyalgia and myofascial pain have been assessed in a blind fashion, specificity has been poor, even though sensitivity has probably remained fairly good as far as palpation tenderness and pain threshold are concerned $(12,19,20)$.

\section{OVERLAP AND NONSPECIFICITY OF CHRONIC SOFT TISSUE PAIN DISORDERS}

Historically, diagnosis has been influenced by dominant theories and the state of medical knowledge in any particular era. In the early part of this century and up to the 1960 s, there was a prevalent condition called 'neuraesthenia'. This diagnosis was made in patients whom we would now diagnose as suffering from anxiety disorders, chronic fibromyalgia, chronic pain disorder and chronic fatigue syndrome. Neuraesthenia was held to be a state of chronic fatigue and debility, thought to be due to psychological maladjustment, although some experts also believed that some cases depended on physiological disturbances and intoxication and/or deficiency states. The clinical description of neuraesthenia included "prolonged feelings of weakness and fatigue, many aches and pains, as well as strange physical sensations. Insomnia and irritability occur often, together with feelings of chronic distress which are associated with a specific organ system of the body. ...Freud also stressed the occurrence of headache, spinal irritation, and dyspepsia, with flatulence and constipation" (21). Most of the symptoms mentioned here are consistent with the modern chronic fibromyalgia and chronic fatigue diagnoses.

It is of some interest that, when blind clinical examination of fibromyalgia and myofascial patients is used, examiners are not able to distinguish between myofascial and chronic fibromyalgia conditions by using bedside clinical examinations for tenderness thresholds, tender point counts, or trigger points and referred pain $(12,19)$.

The lack of apparent specificity of diagnoses can be seen with other comparisons. Most patients with chronic fibromyalgia complain of variable levels of ache, insomnia and fatigue. Chronic fatigue syndrome is likewise characterized by persistent fatigue and insomnia, poor mental efficiency, malaise, variability and often diffuse discomfort. Using the criteria for chronic fatigue syndrome, Goldenberg (22) found that $70 \%$ of patients with chronic fibromyalgia satisfied the criteria for chronic fatigue. Similarly, by using the criteria for fibromyalgia, it was found that two-thirds of a sample of chronic fatigue patients satisfied the criteria for chronic fibromyalgia.

Fatigue is a feature not just of chronic fatigue syndrome - it is also often noted in patients with chronic soft tissue pain. Some investigators have found evidence that this fatigue is a function of general rather than localized factors. Jacobsen and DanneskioldSamsoe (23) reported that muscle strength on movement was reduced in proportion to the number of tender points. Muscle strength, however, did not correlate with spontaneous pain, daily activity or deconditioning. Jacobsen and Danneskiold-Samsoe (24) measured muscular endurance and decline in power during a repetitive knee 
extension exercise in patients with widespread pain and tender points (fibromyalgia), and in patients with localized pain and tender points (myofascial pain). Fibromyalgia patients had lower muscular endurance and a more rapid decline in power. This suggests that fatigue in chronic soft tissue pain may be due to neurophysiological rather than localized muscular factors. Using phosphorus isotope nuclear magnetic resonance spectroscopy, Jacobsen et al (25) found that fibromyalgia subjects had a reduced capacity for voluntary work in comparison with normal controls but a biochemical response to work and recovery similar to that of healthy subjects.

\section{EPIDEMIOLOGICAL EVIDENCE}

While the unique identity of many soft tissue pain diagnoses is subject to debate, there is no doubt that people suffer pain and that sometimes the pain persists well beyond the usual period of tissue healing - sometimes for years. Epidemiological techniques offer methods to study the common factors in painful conditions. An early epidemiological study of pain involved patients in a community family practice unit, and a comparison of pain patients in the community compared with patients referred to a specialty pain clinic $(26,27)$. In these studies, we found that in the adult population in the community the prevalence of 'acute' (or temporary) pain conditions remains stable at $5 \%$, while the prevalence of 'chronic' (or persistent) pain conditions averages $11 \%$, with an increasing prevalence associated with increasing age. Pain severity, health care utilization, emotional distress, attitude, adversarial circumstances of injury or illness behaviour were found to be less of a problem in patients from the family practice group. The prognostic significance of these differences was evident at two years, when $35 \%$ of the family practice patients with persistent pain no longer reported persistent pain, whereas $15 \%$ of the specialty pain clinic patients no longer reported persistent pain (11).

Epidemiological methods are also being used to study the factors on which the diagnosis of chronic fibromyalgia is based. In a study of rheumatic disease clinic patients, Wolfe and Cathey (28) found that $4.3 \%$ had 12 or more tender points and $60 \%$ had no tender points. Tender point counts of 10 or more are about seven times more common in women than men. Wolfe et al (29) found in a community survey that pain all over, sleep disturbance, fatigue and irritable bowel symptoms are four to five times more common in women than in men, and that women have significantly lower tenderness thresholds and higher tender point counts than men. High tender point counts, more than tenderness thresholds, correlate with the typical symptoms of fibromyalgia. A range of tender points from low to very high is found in the general population $(10,29)$.

In an epidemiological study of chronic soft tissue pain in patients drawn from community family practices, Croft et al (10) found that $13 \%$ had chronic widespread pain, $43 \%$ had regional pain and $44 \%$ had no pain. Of those with chronic widespread pain, $40 \%$ had 11 or more tender points, qualifying them for a diagnosis of chronic fibromyalgia. This provides an estimate of about $5 \%$ prevalence of chronic fibromyalgia in the general population. Mean symptom scores for depression, fatigue and sleep problems increased as the tender point counts rose. The authors concluded that tender point scores were significantly and independently related to persistent pain and to depression, fatigue and insomnia. Croft et al
(10) compared the results of an initial postal survey to the results of a subsequent examination done an average of about a year later. They found that, of those who had widespread pain on follow-up, $71 \%$ had widespread pain initially, $22 \%$ had regional pain and $7 \%$ had no pain. Of those who had regional pain on follow-up, $37 \%$ had widespread pain initially, $56 \%$ had regional pain and $12 \%$ had no pain. Of those who had no pain on follow-up, $18 \%$ initially had widespread pain, $26 \%$ had regional pain and $56 \%$ had no pain. In short, pain extent is variable, but those who have widespread pain are more likely to continue to have widespread pain on follow-up. This evidence is consistent with a conclusion that chronic fibromyalgia is not a distinct disease entity but is part of a spectrum of chronic pain and tenderness phenomena, and that variability but not progression tends to characterize chronic soft tissue pain.

No attempts have been made in epidemiological studies to examine the relationship of 'widespread pain complaint', low pain threshold or multiple tender points with respect to variables such as lifestyle, physical activity levels, history of repeated trauma (as in sport), genetic factors or other variables. Hence, we have some information about the prevalence of pain and tenderness, but we cannot hypothesize about epidemiological variables that may influence these pain phenomena.

\section{ACCIDENTS, ILLNESSES AND SOFT TISSUE PAIN}

The question of causation of chronic soft tissue pain has remained troublesome from a medical and legal point of view. Some biological and laboratory correlates for chronic fibromyalgia exist, but not consistently across all patients. Causes proposed include muscle or joint injury, immunological disorder, sleep disturbance or hormonal disturbance (30), but all of these hypotheses are based on anecdotal reports or small samples. Wolfe (30) acknowledged that, although there was a considerable body of research supporting the validity and reliability of assessments for chronic fibromyalgia in clinical settings, "No studies have specifically addressed validity and reliability of ... assessments in fibromyalgia in the work place, compensation, or injury setting". That is to say, it is unknown whether an adversarial motive or financial incentive might be a source of error or bias in diagnosis.

It is clear that soft tissue pain may be found in people who have been injured and in people who have no recollection of a precipitating event or illness. It is also clear that, in people who have been injured, pain in some cases far outlasts the usual period of healing. In chronic soft tissue pain, however, recent research suggests that the problem is due more to a general altered physiology of pain threshold rather than to a regional effect of trauma remaining in the originally injured tissue (12).

Considering that, in the nonpainful members of the average female population, about $10 \%$ will have 10 or more tender points, and that tender points are correlated with symptoms of fatigue and other chronic fibromyalgia symptoms $(10,29)$, one must wonder whether some cases of chronic soft tissue pain (myofascial pain, fibromyalgia or RSI) may be due to intolerance to repetitive movement rather than to actual muscle and soft tissue injury in people who already had multiple tender points, and whether this trait may have been unmasked or aggravated by the job or nonspecific factors.

A model for looking at the question of injury and resulting chronic pain is persons who have had accidents. It is difficult to esti- 
mate the number of persons who experience pain as the result of a traffic accident because many do not make a claim for personal injury and, hence, the claims for injury may underestimate the actual prevalence, but Barnsley et al (31) thought that one per 1000 seems to be a reasonable estimate for Western societies. Comparing various scientifically adequate studies of the long term consequences of rear-end collisions, Barnsley et al (31) reported that between $14 \%$ and $42 \%$ result in chronic neck pain, and $6 \%$ to $28 \%$ result in severe prolonged pain.

Keeping in mind that a range of tender points is found 'naturally' in the general population, if one assumes that $5 \%$ of people who have traffic accidents are also likely to have 11 or more tender points, the question of causality - whether a given accident caused chronic soft tissue pain - becomes an important problem. If an examiner sees a patient only after an accident, and finds multiple tender points and complaint of pain and other subjective symptoms, the possibility of a chance association between accident and multiple tender points (at least $1 \%$ in males and $10 \%$ in females) has to be considered.

\section{REFERENCES}

1. Cameron RS. The cost of long term disability due to fibromyalgia, chronic fatigue syndrome and repetitive strain injury: The private insurance perspective. J Musculoskel Pain 1995;3:169-72.

2. Littlejohn GO. Key issues in repetitive strain injury. J Musculoskel Pain 1995;3:25-33.

3. Atkinson JH, Slater MA, Grant I, Patterson TL, Garfin SR. Depressed mood in chronic low back pain: relationship with stressful life events. Pain 1988;35:47-55.

4. Magni G, Moreschi C, Rigatti-Luchini S, Merskey H. Prospective study on the relationship between depressive symptoms and chronic musculoskeletal pain. Pain 1994;56:289-97.

5. American Psychiatric Association. Diagnostic and Statistical Manual of Mental Disorders, 4th edn. Washington: American Psychiatric Association, 1994.

6. Wolfe F, Smythe HA, Yunus MB, et al. The American College of Rheumatology 1990 Criteria for the Classification of Fibromyalgia. Report of the Multicenter Criteria Committee. Arthritis Rheum 1990;33:160-72.

7. Campbell SM, Clark S, Tindall EA, Forehand ME, Bennett RM. Clinical characteristics of fibrositis: I. A 'blinded' controlled study of symptoms and tender points. Arthr Rheum 1983;26:817-24.

8. Wolfe F, Hawley DJ, Cathey MA, Caro X, Russell IJ. Fibrositis: symptoms frequency and criteria for diagnosis. J Rheumatol $1985 ; 12: 1159-63$.

9. Yunus MB, Masi AT, Aldag JC. Preliminary criteria for primary fibromyalgia syndrome (PFS): multivariate analysis of a consecutive series of PFS, other pain patients, and normal subjects. Clin Exp Rheumatol 1989;7:63-9.

10. Croft P, Schollum J, Silman A. Population study of tender point counts and pain as evidence of fibromyalgia. BMJ 1994;309:696-9.

11. Crook J, Weir R, Tunks E. An epidemiogical follow-up survey of persistent pain sufferers in a group family practice and specialty pain clinic. Pain 1989;36:49-61.

12. Tunks E, McCain GA, Hart LE, et al. The reliability of examination for tenderness in patients with myofascial pain, chronic fibromyalgia and controls. J Rheumatol 1995;22:944-52.

13. Kellgren JH. Observations on referred pain arising from muscle. Clin Sci 1938;3:175-90.

14. Kellgren JH. On the distribution of pain arising from deep somatic structures with charts on segmental pain areas. Clin Sci 1939;4:35-46.

15. Kellgren JH. The anatomical source of back pain. Rheumatol Rehabil 1977;16:3-12.

16. Travell J, Rinzler SH. The myofascial genesis of pain. Postgrad Med 1952;11:425-34.
The question of possible malingering or exaggeration is likewise not to be dismissed lightly. A study of deliberate exaggeration in fibromyalgia subjects found that a blinded observer can achieve $60 \%$ sensitivity in detecting exaggeration, and with the addition of a structured pain assessment can improve this to $90 \%$. At the same time, specificity (avoiding false positive calls) was $86 \%$, with a best overall accuracy of $88 \%$. This indicates that about $15 \%$ of patients might be mislabelled as 'faking', and $10 \%$ to $40 \%$ of 'fakers' may be mislabelled as 'not faking' (32).

In working with such cases of chronic pains associated with injury claims, it is dangerous to become uncautious about attributing pain to an injury only on the strength of the patient's self-report, or to become cynical to the point of frequently disqualifying reports of chronic soft tissue pain. In weighing the probabilities, judgements based on careful data gathering from before and after injuries, attempts to appraise emerging scientific work, and an attitude of humility rather than arrogance will be helpful in providing a balance for fair judgement.

17. Travell JG, Simons DG. Myofascial Pain and Dysfunction: The Trigger Point Manual. Baltimore: Williams and Wilkins, 1983.

18. Simons D. Muscular pain syndromes. In: Fricton JR, Awad E, eds. Advances in Pain Research and Therapy, vol 17. Myofascial Pain and Fibromyalgia. New York: Raven, 1990:1-41.

19. Wolfe F, Simons DG, Fricton J, et al. The fibromyalgia and myofascial pain syndromes: a preliminary study of tender points and trigger points in persons with fibromyalgia, myofascial pain syndrome, and no disease. J Rheumatol 1992;19:944-51.

20. Tunks E. Clinical experimental investigations in fibromyalgia and myofascial pain. In: Vaeroy H, Merskey H, eds. Progress in Fibromyalgia and Myofascial Pain. Amsterdam: Elsevier, 1993:161-72.

21. Chrzanowksi G. Neurasthenia and hypochondriasis. In: Freedman AM, Kaplan HI, eds. Comprehensive Textbook of Psychiatry. Baltimore: Williams and Wilkins, 1967:1163-8.

22. Goldenberg D. Overlap of fibromyalgia, myofascial pain, and chronic fatigue syndrome. J Musculoskel Pain 1995;3:87-91.

23. Jacobsen S, Danneskiold-Samsoe B. Inter-relations between clinical parameters and muscle function in patients with primary fibromyalgia. Clin Exp Rheumatol 1989;7:493-8.

24. Jacobsen S, Danneskiold-Samsoe B. Dynamic muscular endurance in primary fibromyalgia compared with chronic myofascial pain syndrome. Arch Phys Med Rehabil 1992;73:170-3.

25. Jacobsen S, Jensen KE, Thomsen C, Danneskiold-Samsoe B, Henriksen O. [Magnetic resonance spectroscopy in fibromyalgia. A study of phosphate-31 spectra from skeletal muscles during rest and after exercise.] Ugeskr-Laeger 1994;156:6841-4.

26. Crook J, Rideout E, Browne G. The prevalence of pain complaints in a general population. Pain 1984;18:299-314.

27. Crook J, Tunks E, Rideout E, Browne G. Epidemiologic comparison of persistent pain sufferers in a specialty pain clinic and in the community. Arch Phys Med Rehab 1986;67:451-5.

28. Wolfe F, Cathey MA. The epidemiology of tender points: A prospective study of 1520 patients. J Rheumatol 1985;12:1164-8.

29. Wolfe F, Ross K, Anderson J, Russell IJ. Aspects of fibromyalgia in the general population: sex, pain threshold, and fibromyalgia symptoms. J Rheumatol 1995;22:151-6.

30. Wolfe F. The fibromyalgia syndrome: a consensus report on fibromyalgia and disability. J Rheumatol 1996;23:534-9.

31. Barnsley L, Lord S, Bogduk N. Whiplash injury. Pain 1994;58:283-307.

32. Smythe HA, Gladman A, Mader R, Peloso P, Abu-Shakra M. Strategies for assessing pain and pain exaggeration: controlled studies. J Rheumatol 1997;24:1622-9. 


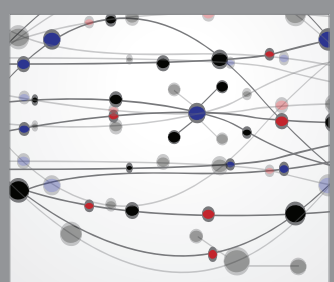

The Scientific World Journal
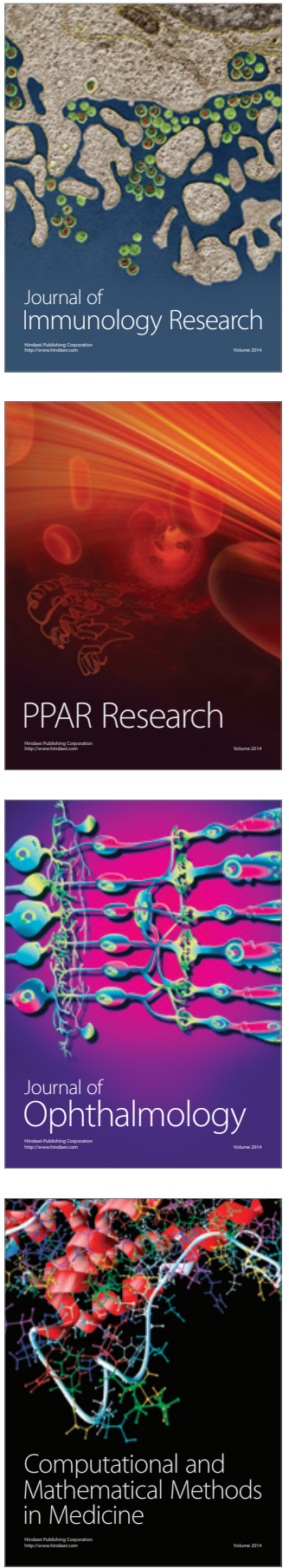

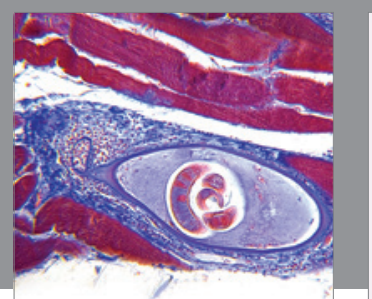

Gastroenterology Research and Practice

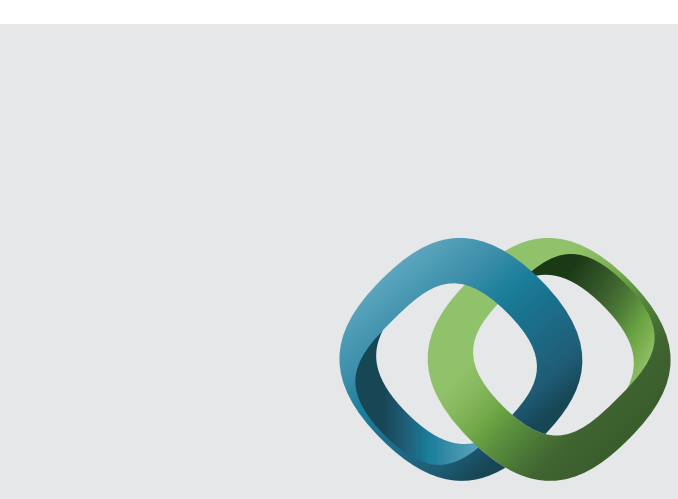

\section{Hindawi}

Submit your manuscripts at

http://www.hindawi.com
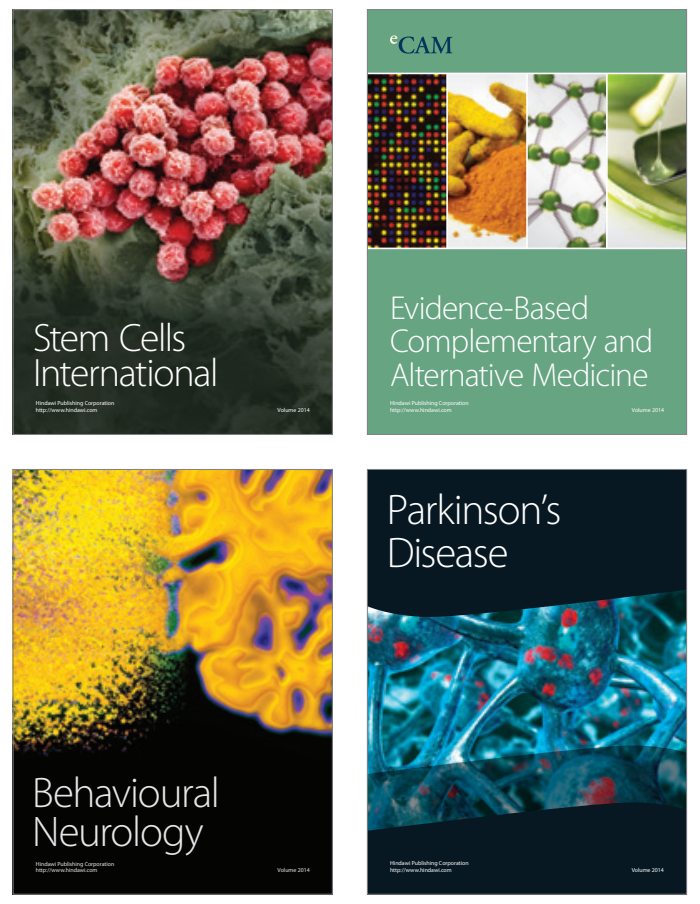
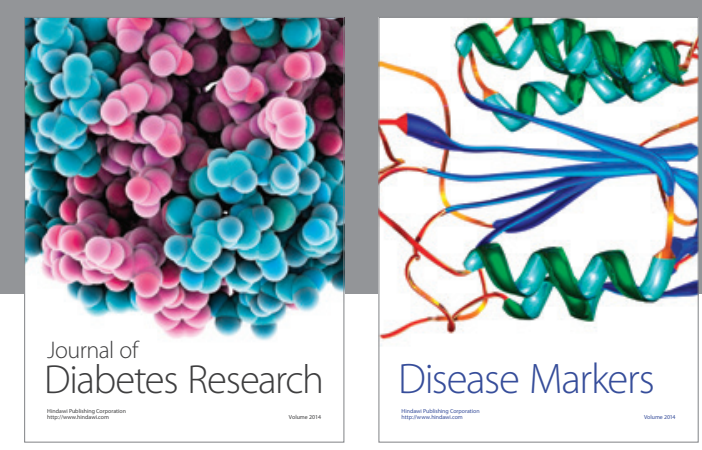

Disease Markers
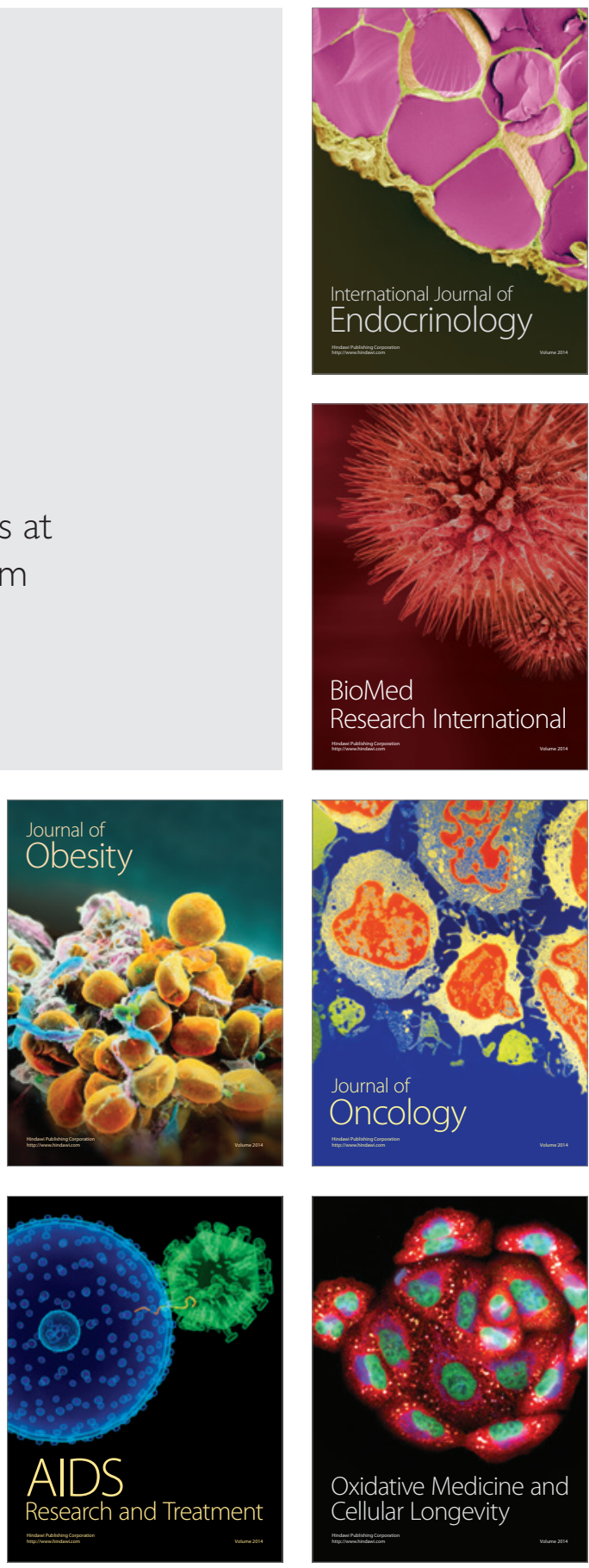